\title{
Bullous pemphigoid: An immune disorder related to aging (Review)
}

\author{
MARIA LUDOVICA DEOTTO, ALICE SPILLER, ALVISE SERNICOLA and MAURO ALAIBAC \\ Dermatology Unit, Department of Medicine, University of Padova, I-35121 Padua, Italy
}

Received July 20, 2021; Accepted September 29, 2021

DOI: $10.3892 /$ etm.2021.10972

\begin{abstract}
Bullous pemphigoid (BP) is the most frequent subepidermal autoimmune blistering disease and is caused by autoantibodies directed against two principal antigens of the hemidesmosome, BP antigen 180 and BP antigen 230. The pathogenesis of BP is dependent upon the interaction between genetic predisposition, physiological skin alterations due to aging and specific triggers. Several triggers have already been reported to induce this disease and include drugs, thermal or electrical burns, surgical procedures, trauma, UV radiation, radiotherapy, chemicals and infections. Data from the current literature support the hypothesis that alterations of the skin barrier associated with aging increase individual susceptibility to these aforementioned triggers. Consequently, this has been reported to lead to the attack of autoantibodies, demonstrating the predilection of BP for the elderly population. The identification of triggering factors and comorbidities may aid in understanding the pathogenesis of $\mathrm{BP}$ and improve clinical management by encouraging their prompt recognition and removal. Moreover, the present review has indicated that current management of BP should be aimed at counteracting the detrimental effects of aging on the skin by restoring skin barrier integrity and maintaining cutaneous homeostasis, for example with systematic applications of topical emollients and photoprotection. This strategy could prove even more beneficial in the elderly, in which frequent comorbidities associated with age often narrow available immunosuppressive treatment options. Furthermore, the safety of treatment regimens may significantly affect outcome and prognosis.
\end{abstract}

Correspondence to: Dr Alvise Sernicola, Dermatology Unit, Department of Medicine, University of Padova, 4 Via Vincenzo Gallucci, I-35121 Padua, Italy

E-mail: alvise.sernicola@me.com

Abbreviations: APC, antigen-presenting cell; BP, bullous pemphigoid; CCL, chemokine $\mathrm{C}-\mathrm{C}$ motif ligand; $\mathrm{CD}$, cluster of differentiation; Ig, immunoglobulin; UVB, ultraviolet B

Key words: bullous pemphigoid, blistering disorder, dermatology, autoimmunity, aging, senescence

\section{Contents}

1. Introduction

2. Triggers of BP

3. Comorbidities of BP

4. Aging

5. Skin changes associated with aging

6. BP and aging

7. Conclusion

\section{Introduction}

Autoimmune bullous diseases are a significant cause of morbidity and mortality, particularly in the elderly population. Given the advancing age of the general population, the incidence of these disorders, particularly that of bullous pemphigoid (BP), is expected to increase. $\mathrm{BP}$ is one of the most frequent subepidermal autoimmune blistering diseases that predominantly affects individuals aged $>60$ years (1). BP is a chronic condition that may resolve spontaneously, although it may take years before remission. The mortality rate of BP is mainly dependent on the age of onset and on the systemic therapies prescribed, rather than on the extent and severity of BP itself.

The typical clinical presentation consists of tense bullae of variable dimensions with clear or hemorrhagic fluid content, forming on erythematous or occasionally on apparently healthy skin (2). The blisters of BP have a high breaking strength and can persist for a few days before rupturing, leaving eroded and crusted areas. These lesions are commonly observed in the lower abdomen, in the anterior and inner thighs and in the flexor region of the forearm, and they are associated with intense itching (3). In certain cases, in which erythematous lesions are predominant, the patient may present with widespread urticarial lesions and no blistering, particularly in the early stages of the disease. Mucous membranes are affected in only a minority of the patients, ranging between 10 and $35 \%$, and the buccal mucosa is mainly involved, displaying blisters or erosions which are generally non-scarring and limited to small parts of mucosa (4).

$\mathrm{BP}$ is a complex multifactorial disorder that is common in elderly patients (5). In the present review, the disease mechanisms and related triggers and comorbidities of BP have been explored, with the aim of highlighting conditions that 
are typically found in elderly patients. The alterations in skin barrier integrity and immune system function associated with aging, which may increase susceptibility to BP in the elderly, are also described.

$\mathrm{BP}$ is the most frequent autoimmune blistering disorder, with a reported prevalence of $>250$ patients/million individuals and an incidence rate of 43 cases/million annually for the general population in the United Kingdom $(6,7)$. It is traditionally considered a disease of the elderly, with the average age of onset ranging from 66-83 years. Furthermore, the incidence rate of BP increases exponentially with age, reaching $190-312$ cases/million each year when considering only individuals over the age of 80 (8). A 300-fold risk increase in developing BP has been estimated in patients aged over 90 compared to individuals of 60 years or younger (9).

BP is a prototypical model of antibody-mediated immune disease. Pathogenic IgG1 and IgG4 autoantibodies are primarily directed against BP antigen 180 (BP180) and BP antigen 230 (BP230), two hemidesmosomal proteins that are components of the dermoepidermal junction (10). The main disease antigen is BP180, also known as type XVII collagen, which is a type II transmembrane protein of the hemidesmosome. However, BP230 is an intracellular cytoplasmic protein and there is controversy as to whether anti-BP230 IgG alone can cause BP (11).

The binding of autoreactive IgG antibodies to BP230 and BP180 antigens initiates a cascade of immunological events, which are detailed in Fig. 1. Complement activation promotes inflammation by summoning leukocytes, mast cells and other immune cell populations to affected skin sites. These cells trigger the release of cytokines, proteases and lysosomal enzymes, which leads to the destruction of hemidesmosomes, exposure of neo-antigens and, ultimately, to the formation of blisters (12). Previous studies have reported that anti-BP180 $\mathrm{IgE}$ autoantibodies are also observed in patients with BP $(13,14)$. Autoimmune IgEs are considered to synergize with self-reactive $\operatorname{IgG} 1$ and $\operatorname{IgG} 4$, leading to complement activation, mast cell degranulation and the release of leukotrienes, platelet-activating factor, TNF and other cytokines. Neutrophils and eosinophils recruited to skin lesion sites release proteolytic enzymes, which impair adhesion molecules and contribute to subepidermal blistering (15).

Although the underlying cause of BP resides in autoimmunity, to the best of our knowledge, it is not known how this loss of self-tolerance occurs and why the elderly population is almost exclusively affected (9). An increase in autoantibody levels is observed with increasing age and may be related to loss of tolerance $(16,17)$. However, with the exception of specific disorders, including BP, the incidence of autoimmune disease in the elderly population is not as high as could be expected.

These observations support the hypothesis that BP is not exclusively dependent on the autoantibodies produced against skin structural proteins, but also requires the development of skin barrier abnormalities. These changes associated with aging, on a background of genetic predisposition, would make elderly subjects susceptible to the action of triggering factors, leading to the exposure of normally sequestered antigens (18).

\section{Triggers of $B P$}

Known triggers of BP include drugs, topically applied products, such as wound dressings, vaccines, viral infections, physical factors, such as UV radiation, radiotherapy, surgery and neurological or cardiac disorders.

Drugs. BP has been frequently associated with systemic therapy. The pathogenesis of drug-induced BP is poorly understood and, in most elderly patients, particularly in the context of polytherapy, it is difficult to establish the triggering role of a specific drug. A complex and multifactorial pathogenesis involving numerous immunological mechanisms has been hypothesized for drug-induced BP. According to the 'two-step' theory, interactions among the immune system and two different drugs displaying similar molecular structures could represent the first and second hit, triggering and enhancing an immune reaction leading to the onset of BP (19). The literature provides an example of 'two-step' induction following intake of captopril and, subsequently, of enalapril. While both drugs are ACE inhibitors, the former also contains a thiol group. The first onset of blisters after captopril is attributed to acantholysis induced by a thiol drug, while relapse after enalapril is associated with the production of autoantibodies and activation of the kinin system caused by the drug (20). Another theory considers the interaction between sulfhydryl groups of hemidesmosomes/components of the basement membrane and sulfur-containing drugs, whereby the integrity of the dermoepidermal junction is disrupted, which could lead to exposure of hidden antigenic sites (21). Furthermore, certain oncological treatments, such as monoclonal antibodies against programmed death-1 and its corresponding ligand, act by inactivating endogenous immunoregulatory checkpoints of T-cell function and they are associated with the development of immune-related adverse events, including cutaneous autoimmune blistering disorders (22). Finally, the emergence of BP following administration of vaccines has been reported in the literature. It has previously been hypothesized that, in predisposed subjects, the inflammatory response following vaccination may promote a conformational change of the dermoepidermal junction and expose hidden epitopes or antigens triggering the production of specific anti-basement membrane antibodies (23).

Infections. Viruses can interact with B and T lymphocytes, stimulating the production of antibodies and the secretion of IL-4 and IL-10, which determines the switch from $\mathrm{T}$ helper type 1 cell (Th1) to T helper type 2 cell (Th2) immunity. Pathogen-induced antibodies may cross-react with shared epitopes on host cells. Furthermore, viruses may induce autoimmunity by directly infecting keratinocytes, exposing hidden epitopes or modifying the expression of existing antigens (24). Host cell fragments can also become inserted into viral envelopes and be presented as novel antigens to the host immune system $(24,25)$. Moreover, cases of BP triggered by Sarcoptes scabiei infestation have been reported. This suggests that parasitic diseases may contribute to the onset of BP, which may be a result of Koebner's phenomenon (26).

Physical factors. The onset of BP has been observed following exposure to numerous physical triggers, including trauma, 


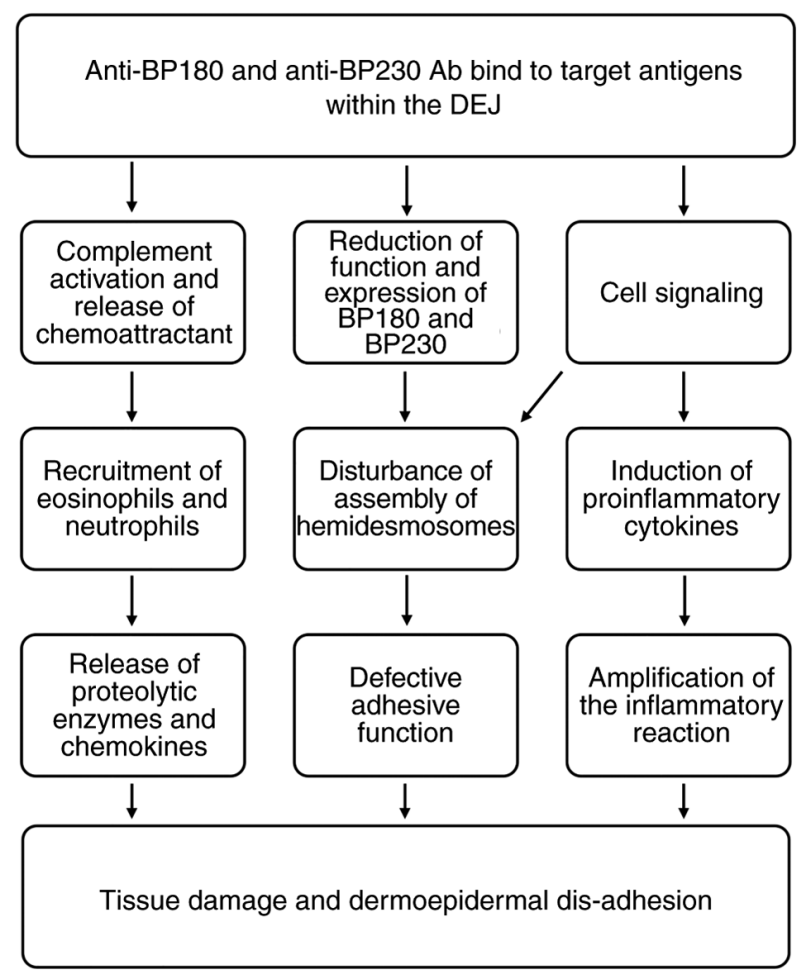

Figure 1. Recognized mechanisms of blister formation in bullous pemphigoid. Ab, antibodies; DEJ, dermoepidermal junction; BP180, BP antigen 180; BP230, BP antigen 230.

surgery, thermal or electrical burns, UV exposure, radiation therapy and photodynamic therapy. The association of BP with radiotherapy, as well as that with thermal or electrical burns, has been documented in a study (27). The irritant mechanism of certain topical drugs on the skin, such as benzyl benzoate, or allergic contact hypersensitivity, for example by 5 -fluorouracil, have been considered as possible triggers for the onset of BP (28). BP can also be induced by UV radiation or photodynamic therapy, both of which are established skin-directed treatment approaches in dermatology (29-33). This hypothesis has been investigated in animal models, which demonstrate that UV irradiation leads to the development of severe inflammation and blisters in subjects with circulating autoantibodies against BP180 or BP230 $(34,35)$. Furthermore, underlying alterations of the basement membrane which are associated with preexisting skin disorders such as psoriasis, are hypothetical predisposing factors (36-38). In patients with psoriasis treated using narrow-band UVB radiation therapy, BP lesions have been reported to develop over pre-existing psoriatic lesions, leading to the hypothesis that UVB- and psolaren UVA-induced antigenic changes in psoriatic skin may trigger blister formation $(39,40)$. The pathogenetic mechanisms by which other environmental physical agents could cause or exacerbate BP are unclear. Previous studies have reported that trauma-induced tissue rupture may lead to the exposure of previously masked antigens and the development of autoantibodies directed towards the basement membrane $(29,41,42)$. Following physical trauma, the damaged tissue may release a variety of pro-inflammatory factors that contribute to the recruitment of circulating inflammatory cells. This would result in the activation of granulocytes and the complement pathway and may lead to the production of antibodies and, finally, blistering (12).

\section{Comorbidities of BP}

An association has been highlighted between BP and a number of conditions, including autoimmune, neurological (43-51) and cardiovascular disorders (47,51-56), as well as tumors (47,51,57-60). These are listed in Table I. The association between BP and certain neurological diseases could be explained by the fact that damage to brain cells exposes neural antigens. These molecules may lead to the production of cross-reactive autoantibodies against antigens of the skin basement membrane (18).

$\mathrm{BP}$ has also been associated with other autoimmune diseases, including lupus erythematosus, lichen planus, membranous nephropathy, pernicious anemia, thyroiditis, primary biliary cirrhosis, multiple sclerosis, psoriasis and polymyositis (61-65). The onset of BP in patients with psoriasis may be a result of a series of epigenetic events involved in the psoriatic inflammatory cascade (66). Moreover, basement membrane changes in psoriasis make the patient more susceptible to autoantibody formation. Furthermore, an increase in chemokine C-C motif ligand (CCL) 28 and T helper type 17 cell (Th17) serum levels has been demonstrated in psoriasis as well as in BP (67). This is consistent with the concept that IL-17-producing Th17 cells are involved in the secretion of pro-inflammatory cytokines and MMPs and in the recruitment of neutrophils and eosinophils, all of which are important factors in the pathogenesis of BP (66).

\section{Aging}

The epidemiology of BP clearly shows that this is a disease of the elderly. Its triggers and comorbidities have been reviewed thus far, highlighting their association with advanced age. The following sections focus on the immune mechanisms associated with aging that contribute to the induction of BP. Aging is accompanied by a gradual remodeling of the immune system called immunosenescence. Immunosenescence is the process of immune system dysregulation, which is characteristic of elderly patients and gives rise to the following three events: i) A reduction in the immune response; ii) an increase in autoantibody production; and iii) chronic, sterile, low-grade inflammation (68).

In elderly individuals, low affinity immunoglobulin production increases, as do the serum levels of IgG1 and IgG4. Chronic production of cytokines and the associated low-grade inflammation is typical of elderly patients and could possibly serve as a stimulus for the onset of autoimmunity (69). Furthermore, persistent infections commonly develop in old age. Infectious agents, in the context of a dysregulated immune system, may provide foreign antigens that cross-react with self-antigens displaying similar sequences. It has also been observed that $\mathrm{CD} 4^{+} \mathrm{CD} 25^{+}$regulatory $\mathrm{T}$ cells decrease with age and, therefore, their protective mechanism against the development of autoimmunity may become gradually compromised (70).

Considering its anatomical characteristics and defensive role against the external environment, the skin serves as 
Table I. Classification of comorbidities reported in association with bullous pemphigoid.

\begin{tabular}{|c|c|c|}
\hline Classification & Disease & (Refs.) \\
\hline Autoimmune diseases & $\begin{array}{l}\text { Psoriasis } \\
\text { Rheumatoid arthritis } \\
\text { Lupus erythematosus } \\
\text { Lichen planus } \\
\text { Polymyositis } \\
\text { Thyroiditis } \\
\text { Pernicious anemia } \\
\text { Primary biliary cirrhosis } \\
\text { Membranous nephropathy }\end{array}$ & $(61-66)$ \\
\hline Neurological diseases & $\begin{array}{l}\text { Parkinson's disease } \\
\text { Alzheimer's disease } \\
\text { Stroke } \\
\text { Dementia } \\
\text { Multiple sclerosis } \\
\text { Epilepsy } \\
\text { Schizophrenia }\end{array}$ & $(43-51)$ \\
\hline Cardiovascular diseases & $\begin{array}{l}\text { Hypertension } \\
\text { Stroke } \\
\text { Venous thromboembolism } \\
\text { Pulmonary embolism }\end{array}$ & $(47,51-56)$ \\
\hline Neoplasms & $\begin{array}{l}\text { Kidney cancer } \\
\text { Laryngeal cancer } \\
\text { Hematological malignancies }\end{array}$ & $(47,51,57-60)$ \\
\hline
\end{tabular}

a barrier organ. It is not merely a mechanical barrier, but a complex immune organ, hosting both innate and adaptive immune functions, with the physiological role of protecting the organism from infectious or inflammatory diseases. The process of aging is particularly evident in the cutaneous compartment, which is vulnerable to intrinsic alterations and to lifelong environmental exposure (71). Intrinsic factors mainly include hormonal changes, such as those related to menopause, ethnicity, which affects pigmentation and lipid proportions, and stress, which may exaggerate degenerative processes (72-74). The influence of the environment on skin aging is mainly dependent on air pollutants and sunlight $(75,76)$.

\section{Skin changes associated with aging}

Skin aging is a slow, complex process resulting from the interplay of cellular, molecular and genetic factors. Different cutaneous layers undergo progressive morphological and functional changes that alter the appearance and mechanical behavior of the skin (77). The principal changes that make elderly individuals more susceptible to mechanical injury, alter the skin microbiome and impair skin barrier immune function, contributing to the onset of chronic low-grade inflammation, are summarized in Table II.

Senescence of the epidermis is accompanied by a dull appearance, pigmentation and dehydration (77). The epidermis of aged skin exhibits an overall decreased thickness, whereas that of the basement membrane may increase up to $50 \%$ with aging. However, collagen IV content is decreased in the basement membrane, reflecting a reduction in tissue turnover (78). Keratinocytes acquire degenerative morphological changes due to a loss of epidermal cell stemness, as well as reduced support and nutrition from the underlying dermis (79). A thinning of the epidermis, with atrophy of the keratinocytes, consequently leads to increases in trans-epidermal water loss and skin dryness $(80,81)$. Melanocytes are responsible for cellular hyperpigmentation of senescent skin due to an enhanced dihydroxyphenylalanine reaction following chronic irradiation (82).

Dermal alterations are a result of UVA-induced photoaging, mediated by an increase in cellular reactive oxygen species and a decrease in the thickness of the dermis, elastosis and fibroblast apoptosis. These aforementioned factors are responsible for wrinkles, dehydration, scar formation and skin susceptibility to trauma $(83,84)$. A decrease in the number and size of dermal fibroblasts has been demonstrated to be associated with skin thinning and the reduced production of pro-collagen (85). Moreover, an accumulation of senescent dermal fibroblasts is known to occur with aging and is classically defined by the expression of cyclin-dependent kinase inhibitor 2A in the skin of elderly individuals and mice (86-88). Senescent fibroblasts are characterized by irreversible cell growth arrest and changes in the levels of secretory proteins involved in inflammation and matrix degradation. Secretion of proinflammatory mediators, such as IL-8, IL-6, TNF and CCL2, is upregulated and sustains chronic inflammation (89). 
Table II. Changes in cutaneous barrier function and local skin immunity associated with aging.

\begin{tabular}{ll}
\hline Skin function & \multicolumn{1}{c}{ Associated change } \\
\hline Inflammation & $\uparrow$ Senescent cells \\
& $\uparrow$ Cytokines of inflammaging \\
& $\uparrow$ MMP production (with ECM degradation) \\
Phagocytosis & $\downarrow$ TNF production \\
& $\downarrow$ LC number \\
& $\downarrow$ LC migration \\
T cell function & $\downarrow$ Response to antigens \\
& $\uparrow$ FOXP3 regulatory T cells \\
& $($ inhibit antigen-specific immunity) \\
& $\uparrow$ Inhibitory receptors \\
Stromal support & $\downarrow$ ECM production by fibroblasts \\
& $\downarrow$ Ability of fibroblasts to differentiate \\
& $\downarrow$ Dermal white adipose tissue
\end{tabular}

ECM, extracellular matrix; FOXP3, forkhead box P3; LC, Langerhans cell; $\uparrow$, increase; $\downarrow$, decrease.

Furthermore, increased expression levels of MMPs, including MMP-1,-3 and -9, in senescent skin decreases the total amount of collagen and is also responsible for the fragmentation of elastin, which results in reduced skin elasticity and classic signs of skin aging, such as wrinkles (90). Elastin is an inert protein that forms during early development and is not replenished, so any loss in elastin that occurs throughout life tends to be irreversible (91). In photoaged skin, collagen and elastin content are both reduced by $\sim 50 \%$, which means that hydration, tensile strength and elasticity are compromised (92). The dermis also hosts sweat glands that, although they may show atrophy, generally continue to function in elderly individuals.

With advancing age, wasting of subcutaneous adipose tissue is observed due to a reduction in the number of white adipocytes (93). This change affects the mechanical protection as well as antimicrobial defense that is physiologically provided from dermal fat in response to infection (94). Dermal adipocytes may promote innate immunity through production of antimicrobial peptide cathelicidin, and may support adaptive immunity by providing a hub for memory $\mathrm{T}$ cells (95). The enhancement of transforming growth factor $b$ pathway in the elderly is largely responsible for this age-dependent loss of immune protection from dermal fat (94).

Immune compartments of the skin are impaired following changes in Langerhans cell function, weakening of antigen-specific responses and modification of regulatory T-cell populations (96). These changes occur in the context of chronic low-grade inflammation that is typical of senescence and has been defined as 'inflammaging'. Potential markers of inflammaging include C-reactive protein, which is characteristically elevated in the serum, and IL- $1 \beta$, the elevation of which is associated with increased morbidity and mortality in elderly patients (69). Macrophages may also contribute to the development of inflammaging due to structural changes in the skin, such as thinning. These innate immune cells are more easily exposed to pathogens leading to chronic activation and cytokine production (97). Moreover, the accumulation of senescent cells was also shown to contribute to increased inflammation in the elderly (98).

In summary, changes impairing the physical, chemical and immunological barrier function of the skin are all likely culprits responsible for susceptibility to BP in genetically predisposed elderly individuals who have been exposed to specific triggers.

\section{BP and aging}

Aging significantly alters the anatomy and function of the skin. A triggering factor on damaged skin easily destroys keratinocytes via necrosis or necroptosis, releasing into the extracellular space intracellular components that act as autoantigens (99). BP180 and BP230 are autoantigens taken up by specialized antigen presenting cells (APC), which express the class II major histocompatibility complex. APCs present to self-reactive $\mathrm{T}$ cells leading to an adaptive immune response and the release of pro-inflammatory cytokines from activated T cells (100). Subsequently, this leads to an increase in co-stimulatory receptors on the surface of APCs and to the activation of autoreactive autoantibody-producing B cells. Furthermore, certain molecules released following cell damage may behave as autoantigens and endogenous Toll-like receptor (TLR) ligands. TLRs and B-cell receptors can be directly activated triggering the secretion of autoantibodies. These antibodies must then acquire pathogenicity by performing a class switch from IgM to IgA or IgG. Damaged keratinocytes also release additional self-antigens that contribute to the production of new autoantibodies and further impairment of the skin barrier, which establishes a perpetual cycle of tissue damage and autoantibody production $(10,14)$.

\section{Conclusion}

The pathology of BP results from the complex interaction of multiple mechanisms, including genetic predisposition, skin barrier changes, immunosenescence and triggering factors. The epidemiology of BP displays a predilection for elderly individuals. In the present review, the triggers and comorbidities associated with BP have been described, highlighting conditions that are typically found in advanced age. Moreover, the effects of aging on skin barrier integrity and the role of immune system function in BP susceptibility were investigated.

The present review has indicated that the management of BP should be aimed at removing potential triggers, treating concomitant disease conditions and counteracting the detrimental effects of aging on the skin. The latter objective may be achieved by improving skin barrier integrity and maintaining cutaneous homeostasis, for example with systematic applications of topical emollients and photoprotection. Furthermore, immunosuppressive treatment for BP must be tailored according to the presence of comorbidities, age and overall clinical conditions of each patient (101).

In conclusion, restoring skin barrier integrity should be a treatment goal for all patients with BP. This strategy could prove particularly beneficial in elderly individuals, in whom frequent comorbidities associated with age often limit the 
availability of treatment options. Moreover, the safety of regimens can markedly affect outcome and prognosis.

\section{Acknowledgements}

Not applicable.

\section{Funding}

No funding was received.

\section{Availability of data and materials}

Not applicable.

\section{Authors' contributions}

MLD and ASp were responsible for data collection and the writing of the draft manuscript. ASe was responsible for reviewing, editing and the presentation of data in the manuscript. MA was responsible for the concept of the review and supervision and for reviewing and editing the manuscript. All authors read and approved the final manuscript. Data sharing is not applicable.

\section{Ethics approval and consent to participate}

Not applicable.

\section{Patient consent for publication}

Not applicable.

\section{Competing interests}

The authors declare that they have no competing interests.

\section{References}

1. Parker SR and MacKelfresh J: Autoimmune blistering diseases in the elderly. Clin Dermatol 29: 69-79, 2011.

2. Bernard P and Antonicelli F: Bullous pemphigoid: A review of its Diagnosis, Associations and Treatment. Am J Clin Dermatol 18: 513-528, 2017.

3. Miyamoto D, Santi CG, Aoki V and Maruta CW: Bullous pemphigoid. An Bras Dermatol 94: 133-146, 2019.

4. Patel F, Wilken R, Patel FB, Sultani H, Bustos I, Duong C, Zone JJ, Raychaudhuri SP and Maverakis E: Pathophysiology of autoimmune bullous diseases: Nature versus nurture. Indian J Dermatol 62: 262-267, 2017.

5. Yang M, Wu H, Zhao M, Chang C and Lu Q: The pathogenesis of bullous skin diseases. J Transl Autoimmun 2: 100014, 2019.

6. Marazza G, Pham HC, Schärer L, Pedrazzetti PP, Hunziker T, Trüeb RM, Hohl D, Itin P, Lautenschlager S, Naldi L, et al: Incidence of bullous pemphigoid and pemphigus in Switzerland: A 2-year prospective study. Br J Dermatol 161: 861-868, 2009.

7. Langan SM, Smeeth L, Hubbard R, Fleming KM, Smith CJ and West J: Bullous pemphigoid and pemphigus vulgaris-incidence and mortality in the UK: Population based cohort study. BMJ 337: a180, 2008.

8. Gudi VS, White MI, Cruickshank N, Herriot R, Edwards SL, Nimmo F and Ormerod AD: Annual incidence and mortality of bullous pemphigoid in the Grampian Region of North-east Scotland. Br J Dermatol 153: 424-427, 2005.

9. Hübner F, Recke A, Zillikens D, Linder R and Schmidt E: Prevalence and age distribution of pemphigus and pemphigoid diseases in Germany. J Invest Dermatol 136: 2495-2498, 2016.
10. Feliciani C, Caldarola G, Kneisel A, Podstawa E, Pfütze M, Pfützner W and Hertl M: IgG autoantibody reactivity against bullous pemphigoid (BP) 180 and BP230 in elderly patients with pruritic dermatoses. Br J Dermatol 161: 306-312, 2009.

11. Hopkinson SB and Jones JC: The N terminus of the transmembrane protein BP180 interacts with the N-terminal domain of BP230, thereby mediating keratin cytoskeleton anchorage to the cell surface at the site of the hemidesmosome. Mol Biol Cell 11: 277-286, 2000.

12. Giang J, Seelen MAJ, van Doorn MBA, Rissmann R, Prens EP and Damman J: Complement activation in inflammatory skin diseases. Front Immunol 9: 639, 2018.

13. Fania L, Caldarola G, Müller R, Brandt O, Pellicano R, Feliciani $\mathrm{C}$ and Hertl M: IgE recognition of bullous pemphigoid (BP)180 and BP230 in BP patients and elderly individuals with pruritic dermatoses. Clin Immunol 143: 236-245, 2012.

14. Di Zenzo G, Thoma-Uszynski S, Fontao L, Calabresi V, Hofmann SC, Hellmark T, Sebbag N, Pedicelli C, Sera F, Lacour JP, et al: Multicenter prospective study of the humoral autoimmune response in bullous pemphigoid. Clin Immunol 128: 415-426, 2008

15. Park SH, Lee SH, Kim JH and Kim SC: Circulating eosinophil and neutrophil counts correlate with disease severity in bullous pemphigoid. Ann Dermatol 30: 544-549, 2018.

16. Budamagunta V, Foster TC and Zhou D: Cellular senescence in lymphoid organs and immunosenescence. Aging (Albany NY) 13: 19920-19941, 2021.

17. Liu YD, Wang YH, Ye YC, Zhao WL and Li L: Prognostic factors for mortality in patients with bullous pemphigoid: a meta-analysis. Arch Dermatol Res 309: 335-347, 2017.

18. Lai YC, Yew YW and Lambert WC: Bullous pemphigoid and its association with neurological diseases: A systematic review and meta-analysis. J Eur Acad Dermatology Venereol 30: 2007-2015, 2016.

19. Adam J, Pichler WJ and Yerly D: Delayed drug hypersensitivity: Models of T-cell stimulation. Br J Clin Pharmacol 71: 701-707, 2011.

20. Ruocco V, Satriano RA and Guerrera V: 'Two-step' pemphigus induction by ACE-inhibitors. Int J Dermatol 31: 33-36, 1992.

21. Ruocco V and Sacerdoti G: Pemphigus and Bullous pemphigoid due to drugs. Int J Dermatol 30: 307-312, 1991.

22. Faina V, Sernicola A, Russo I, Michelotto A, Szathvary V, Frigo AC and Alaibac M: Programmed cell death-1 rs2227981 polymorphism in patients with autoimmune skin blistering disorders: A pilot study. Meta Gene 26: 100793, 2020.

23. Stavropoulos PG, Soura E and Antoniou C: Drug-induced pemphigoid: A review of the literature. J Eur Acad Dermatology Venereol 28: 1133-1140, 2014.

24. Lo Schiavo A, Ruocco E, Brancaccio G, Caccavale S, Ruocco V and Wolf R: Bullous pemphigoid: Etiology, pathogenesis, and inducing factors: Facts and controversies. Clin Dermatol 31: 391-399, 2013.

25. Drago F, Nozza P, Casazza S, Brusati C, Bandelloni R and Rebora A: Human herpesviruses in bullous pemphigoid lesions. Br J Dermatol 152: 375-376, 2005.

26. Iriki $\mathrm{H}$, Adachi $\mathrm{T}$, Matsuda $\mathrm{H}$, Chinen $\mathrm{K}$, Arakawa $\mathrm{H}$, Yamagami J, Nishie W and Yokouchi M: Case of dipeptidyl peptidase 4 inhibitor-associated bullous pemphigoid that developed after a scabies infestation. J Dermatol 47: e258-e260, 2020.

27. Mai Y, Nishie W, Sato K, Hotta M, Izumi K, Ito K, Hosokawa K and Shimizu H: Bullous pemphigoid triggered by thermal burn under medication with a dipeptidyl peptidase-IV inhibitor: A case report and review of the literature. Front Immunol 9: 542 , 2018.

28. Vassileva S: Drug-induced pemphigoid: Bullous and cicatricial. Clin Dermatol 16: 379-387, 1998

29. Dănescu S, Chiorean R, Macovei V, Sitaru C and Baican A: Role of physical factors in the pathogenesis of bullous pemphigoid: Case report series and a comprehensive review of the published work. J Dermatol 43: 134-140, 2016.

30. Caca-Biljanovska N, Arsovska-Bezhoska I and V'lckova-Laskoska M: PUVA-induced bullous pemphigoid in psoriasis. Acta Dermatovenerol Croat 24: 214-217, 2016.

31. Perl S, Rappersberger K, Födinger D, Anegg B, Hönigsmann H and Ortel B: Bullous pemphigoid induced by PUVA therapy. Dermatology 193: 245-247, 1996.

32. Preesman AH, Toonstra J, Van der Putte SC, De Geer DB, Van Weelden H and Van Vloten WA: UV-B-induced bullous pemphigoid restricted to mycosis fungoides plaques. Clin Exp Dermatol 15: 363-366, 1990. 
33. Korekawa A, Kaneko T, Nakajima K, Rokunohe D, Akasaka E, Nakano H, Sawamura D, Fukui T, Takiyoshi N, Kitamura H and Harada K: Mycosis fungoides bullosa associated with bullous pemphigoid. Int J Dermatol 54: e366-e368, 2015.

34. Mitsuhashi Y, Nakano H, Murai T, Ohta T, Sawamura D, Hanada $\mathrm{K}$ and Hashimoto I: Bullous pemphigoid sera induce bullous-pemphigoid-like lesions in neonatal mice pretreated with a limited dose of ultraviolet B irradiation. Dermatology 189 (Suppl 1): S76-S81, 1994.

35. Hall RP III, Murray JC, McCord MM, Rico MJ and Streilein RD: Rabbits Immunized with a Peptide Encoded for by the 230-kD bullous pemphigoid antigen cDNA develop an enhanced inflammatory response to UVB irradiation: A potential animal model for bullous pemphigoid. J Invest Dermatol 101: 9-14, 1993.

36. Ho YH, Hu HY, Chang YT, Li CP and Wu CY: Psoriasis is associated with increased risk of bullous pemphigoid: A nationwide population-based cohort study in Taiwan. J Dermatol 46 604-609, 2019

37. Barnadas MA, Gilaberte M, Pujol R, Agustí M, Gelpí C and Alomar A: Bullous pemphigoid in a patient with psoriasis during the course of PUVA therapy: Study by ELISA test. Int J Dermatol 45: 1089-1092, 2006

38. Wilczek A and Sticherling M: Concomitant psoriasis and bullous pemphigoid: Coincidence or pathogenic relationship? Int J Dermatol 45: 1353-1357, 2006.

39. Danno K, Takigawa M and Horio T: Alterations in lectin binding to the epidermis following treatment with 8-methoxypsoralen plus long-wave ultraviolet radiation. J Invest Dermatol 82 : 176-179, 1984

40. George PM: Bullous pemphigoid possibly induced by psoralen plus ultraviolet a therapy. Photodermatol Photoimmunol Photomed 11: 185-187, 1996.

41. Yesudian PD, Dobson CM, Ahmad R and Azurdia RM: Trauma-induced bullous pemphigoid around venous access site in a haemodialysis patient. Clin Exp Dermatol 27: 70-72, 2002.

42. Neville JA and Yosipovitch G: Flare of bullous pemphigoid in surgically treated skin. Cutis 75: 169-170, 2005.

43. Taghipour K, Chi CC, Vincent A, Groves RW, Venning V and Wojnarowska F: The association of bullous pemphigoid with cerebrovascular disease and dementia: A case-control study. Arch Dermatol 146: 1251-1254, 2010.

44. Langan SM, Groves RW and West J: The relationship between neurological disease and bullous pemphigoid: A population-based case-control study. J Invest Dermatol 131: 631-636, 2011.

45. Brick KE, Weaver CH, Savica R, Lohse CM, Pittelkow MR, Boeve BF, Gibson LE, Camilleri MJ and Wieland CN: A population-based study of the association between bullous pemphigoid and neurologic disorders. J Am Acad Dermatol 71: 1191-1197, 2014.

46. Gambichler T, Segert H, Höxtermann S, Schmitz L, Altmeyer P and Teegen B: Neurological disorders in patients with bullous pemphigoid: clinical and experimental investigations. J Eur Acad Dermatology Venereol 29: 1758-1762, 2015.

47. Kibsgaard L, Bay B, Deleuran M and Vestergaard C: A retrospective consecutive case-series study on the effect of systemic treatment, length of admission time, and co-morbidities in 98 bullous pemphigoid patients admitted to a tertiary centre Acta Derm Venereol 95: 307-311, 2015.

48. Försti AK, Jokelainen J, Ansakorpi H, Seppänen A, Majamaa K Timonen $\mathrm{M}$ and Tasanen K: Psychiatric and neurological disorders are associated with bullous pemphigoid-a nationwide finnish care register study. Sci Rep 6: 37125, 2016.

49. Khosravani S, Handjani F, Alimohammadi R and Saki N: Frequency of neurological disorders in bullous pemphigoid patients: A cross-sectional study. Int Sch Res Notices 2017: 6053267, 2017.

50. Ravn AH, Thyssen JP and Egeberg A: Skin disorders in Parkinson's disease: Potential biomarkers and risk factors. Clin Cosmet Investig Dermatol 10: 87-92, 2017.

51. Kalińska-Bienias A, Kowalczyk E, Jagielski P, Bienias P, Kowalewski C and Wozniak K: The association between neurological diseases, malignancies and cardiovascular comorbidities among patients with bullous pemphigoid: Case-control study in a specialized Polish center. Adv Clin Exp Med 28: 637-642, 2019.

52. Langan SM, Hubbard R, Fleming $\mathrm{K}$ and West J: A population-based study of acute medical conditions associated with bullous pemphigoid. Br J Dermatol 161: 1149-1152, 2009.

53. Heelan K, Mahar AL, Walsh S and Shear NH: Pemphigus and associated comorbidities: A cross-sectional study. Clin Exp Dermatol 40: 593-599, 2015
54. Kremer N, Zeeli T, Sprecher E and Geller S: Failure of initial disease control in bullous pemphigoid: A retrospective study of hospitalized patients in a single tertiary center. Int J Dermatol 56: 1010-1016, 2017

55. Hsu DY, Brieva J, Nardone B, West D and Silverberg JI: Association of pemphigus and systemic corticosteroid use with comorbid health disorders: A case-control study. Dermatol Online J 23: 13030/qt1vk2m30m, 2017.

56. Ungprasert $\mathrm{P}$, Wijarnpreecha $\mathrm{K}$ and Thongprayoon $\mathrm{C}$ : Risk of venous thromboembolism in patients with bullous pemphigoid: A systematic review and meta-analysis. Indian J Dermatol Venereol Leprol 84: 22-26, 2018.

57. Venning VA and Wojnarowska F: The association of bullous pemphigoid and malignant disease: A case control study. $\mathrm{Br}$ J Dermatol 123: 439-445, 1990.

58. Bastuji-Garin S, Joly P, Lemordant P, Sparsa A, Bedane C, Delaporte E, Roujeau JC, Bernard P, Guillaume JC, Ingen-Housz-Oro $\mathrm{S}$, et al: Risk factors for bullous pemphigoid in the elderly: A prospective case-control study. J Invest Dermatol 131: 637-643, 2011.

59. Schulze F, Neumann K, Recke A, Zillikens D, Linder R and Schmidt E: Malignancies in Pemphigus and Pemphigoid Diseases. J Invest Dermatol 135: 1445-1447, 2015.

60. Balestri R, Magnano M, La Placa M, Patrizi A, Angileri L, Tengattini $\mathrm{V}$ and Bardazzi F: Malignancies in bullous pemphigoid: A controversial association. J Dermatol 43: 125-133, 2016.

61. Callen JP: Internal disorders associated with bullous disease of the skin. A critical review. J Am Acad Dermatol 3: 107-119, 1980.

62. Dahl MV: Bullous pemphigoid: Associated diseases. Clin Dermatol 5: 64-70, 1987.

63. Chen YJ, Wu CY, Lin MW, Chen TJ, Liao KK, Chen YC, Hwang CY, Chu SY, Chen CC, Lee DD, et al: Comorbidity profiles among patients with bullous pemphigoid: A nationwide population-based study. Br J Dermatol 165: 593-599, 2011.

64. Ljubojevic S and Lipozenčić J: Autoimmune bullous diseases associations. Clin Dermatol 30: 17-33, 2012.

65. Akarsu S, Özbağçivan Ö, Dolaş N and Aktan Ş: Possible triggering factors and comorbidities in newly diagnosed autoimmune bullous diseases. Turkish J Med Sci 47: 832-840, 2017.

66. Dainichi T and Kabashima K: Interaction of psoriasis and bullous diseases. Front Med 5: 222, 2018.

67. Harper EG, Guo C, Rizzo H, Lillis JV, Kurtz SE, Skorcheva I, Purdy D, Fitch E, Iordanov M and Blauvelt A: Th17 cytokines stimulate CCL20 expression in keratinocytes in vitro and in vivo: Implications for psoriasis pathogenesis. J Invest Dermatol 129: 2175-2183, 2009

68. Watad A, Bragazzi NL, Adawi M, Amital H, Toubi E, Porat BS and Shoenfeld Y: Autoimmunity in the elderly: Insights from basic science and clinics-a mini-review. Gerontology 63: 515-523, 2017.

69. Lee YI, Choi S, Roh WS, Lee JH and Kim TG: Cellular senescence and inflammaging in the skin microenvironment. Int J Mol Sci 22: 3849, 2021

70. Scott MM and Liang SY: Infections in older adults. Emerg Med Clin North Am 39: 379-394, 2021

71. Ganceviciene R, Liakou AI, Theodoridis A, Makrantonaki E and Zouboulis CC: Skin anti-aging strategies. Dermatoendocrinol 4: 308-319, 2012.

72. Raine-Fenning NJ, Brincat MP and Muscat-Baron Y: Skin aging and menopause: Implication for treatment. Am J Clin Dermatol 4: 371-378, 2003.

73. Farage MA, Miller KW, Elsner P and Maibach HI: Intrinsic and extrinsic factors in skin ageing: A review. Int J Cosmet Sci 30: 87-95, 2008.

74. Chen Y and Lyga J: Brain-skin connection: Stress, inflammation and skin aging. Inflamm Allergy Drug Targets 13: 177-190, 2014.

75. Schikowski T and Hüls A: Air pollution and skin aging. Curr Environ Health Rep 7: 58-64, 2020.

76. Nakyai W, Saraphanchotiwitthaya A, Viennet C, Humbert P and Viyoch J: An in vitro model for fibroblast photoaging comparing single and repeated UVA irradiations. Photochem Photobiol 93: 1462-1471, 2017.

77. Bhatia E, Kumari D, Sharma S, Ahamad N and Banerjee R: Nanoparticle platforms for dermal antiaging technologies: Insights in cellular and molecular mechanisms. Wiley Interdiscip Rev Nanomed Nanobiotechnol: Aug 22, 2021 (Epub ahead of print).

78. Xi YP, Nette EG, King DW and Rosen M: Age-related changes in normal human basement membrane. Mech Ageing Dev 19: $315-324,1982$. 
79. Bonté F, Girard D, Archambault JC and Desmoulière A: Skin changes during ageing. Subcell Biochem 91: 249-280, 2019.

80. Waller JM and Maibach HI: Age and skin structure and function, a quantitative approach (I): Blood flow, $\mathrm{pH}$, thickness, and ultrasound echogenicity. Ski Res Technol 11: 221-235, 2005.

81. Wilhelm KP, Cua AB and Maibach HI: Skin aging. Effect on transepidermal water loss, stratum corneum hydration, skin surface $\mathrm{pH}$, and casual sebum content. Arch Dermatol 127: 1806-1809, 1991

82. Gilchrest BA, Blog FB and Szabo G: Effects of aging and chronic sun exposure on melanocytes in human skin. J Invest Dermatol 73: 141-143, 1979.

83. Trivisonno A, Rossi A, Monti M, Di Nunno D, Desouches C, Cannistra $\mathrm{C}$ and Toietta G: Facial skin rejuvenation by autologous dermal microfat transfer in photoaged patients: Clinical evaluation and skin surface digital profilometry analysis. J Plast Reconstr Aesthetic Surg 70: 1118-1128, 2017.

84. Buranasirin P, Pongpirul K and Meephansan J: Development of a global subjective skin aging assessment score from the perspective of dermatologists. BMC Res Notes 12: 364, 2019.

85. Mine S, Fortunel NO, Pageon H and Asselineau D: Aging alters functionally human dermal papillary fibroblasts but not reticular fibroblasts: A new view of skin morphogenesis and aging. PLoS One 3: e4066, 2008

86. Hall BM, Balan V, Gleiberman AS, Strom E, Krasnov P Virtuoso LP, Rydkina E, Vujcic S, Balan K, Gitlin I, et al: Aging of mice is associated with p16(Ink4a)- and $\beta$-galactosidase-positive macrophage accumulation that can be induced in young mice by senescent cells. Aging (Albany NY) 8: 1294-1315, 2016.

87. Ressler S, Bartkova J, Niederegger H, Bartek J, Scharffetter-Kochanek K, Jansen-Durr P and Wlaschek M: p16 INK4A is a robust in vivo biomarker of cellular aging in human skin. Aging Cell 5: 379-389, 2006.

88. Pereira BI, Devine OP, Vukmanovic-Stejic M, Chambers ES, Subramanian P, Patel N, Virasami A, Sebire NJ, Kinsler V, Valdovinos A, et al: Senescent cells evade immune clearance via HLA-E-mediated NK and $\mathrm{CD}^{+} \mathrm{T}$ cell inhibition. Nat Commun 10: 2387, 2019.

89. Waldera Lupa DM, Kalfalah F, Safferling K, Boukamp P, Poschmann G, Volpi E, Götz-Rösch C, Bernerd F, Haag L, Huebenthal U, et al: Characterization of skin aging-associated secreted proteins (SAASP) produced by dermal fibroblasts isolated from intrinsically aged human skin. J Invest Dermatol 135: 1954-1968, 2015.
90. Fligiel SE, Varani J, Datta SC, Kang S, Fisher GJ and Voorhees JJ: Collagen degradation in aged/photodamaged skin in vivo and after exposure to matrix metalloproteinase-1 in vitro. J Invest Dermatol 120: 842-848, 2003.

91. Le Page A, Khalil A, Vermette P, Frost EH, Larbi A, Witkowski JM and Fulop T: The role of elastin-derived peptides in human physiology and diseases. Matrix Biol 84: 81-96, 2019.

92.Zhang Z, Zhu H, Zheng Y, Zhang L, Wang X, Luo Z, Tang J, Lin L, Du Z and Dong C: The effects and mechanism of collagen peptide and elastin peptide on skin aging induced by D-galactose combined with ultraviolet radiation. J Photochem Photobiol B 210: 111964, 2020.

93. Farage MA, Miller KW, Elsner P and Maibach HI: Functional and physiological characteristics of the aging skin. Aging Clin Exp Res 20: 195-200, 2008.

94. Zhang LJ, Chen SX, Guerrero-Juarez CF, Li F, Tong Y, Liang Y, Liggins M, Chen X, Chen H, Li M, et al: Age-related loss of innate immune antimicrobial function of dermal fat is mediated by transforming growth factor beta. Immunity 50: 121-136.e5, 2019.

95.Zhang L, Guerrero-Juarez CF, Hata T, Bapat SP, Ramos R, Plikus MV and Gallo RL: Innate immunity. Dermal adipocytes protect against invasive Staphylococcus aureus skin infection. Science 347: 67-71, 2015.

96. Chambers ES and Vukmanovic-Stejic M: Skin barrier immunity and ageing. Immunology 160: 116-125, 2020.

97. Guimarães GR, Almeida PP, de Oliveira Santos L, Rodrigues LP, de Carvalho JL and Boroni M: Hallmarks of aging in macrophages: Consequences to skin inflammaging. Cells 10: 1323, 2021.

98. Low E, Alimohammadiha G, Smith LA, Costello LF, Przyborski SA, von Zglinicki T and Miwa S: How good is the evidence that cellular senescence causes skin ageing? Ageing Res Rev 71: 101456, 2021.

99. Stevens NE, Cowin AJ and Kopecki Z: Skin barrier and autoimmunity-mechanisms and novel therapeutic approaches for autoimmune blistering diseases of the skin. Front Immunol 10: $1089,2019$.

100. Liu Y, Li L and Xia Y: BP180 is critical in the autoimmunity of bullous pemphigoid. Front Immunol 8: 1752, 2017.

101. Hooten J, Hall RP III and Cardones A: Updates on the management of autoimmune blistering diseases. Skin Therapy Lett 19 $1-6,2014$. 